\title{
Sistem Kontrol Troli Rotari sebagai Tempat Penitipan Barang Otomatis menggunakan Fuzzy Logic
}

\section{RISNANDA SATRIATAMA ${ }^{1}$, DENNY DARLIS ${ }^{2}$, PORMAN PANGARIBUAN ${ }^{1}$}

\author{
${ }^{1}$ Teknik Elektro Universitas Telkom, Indonesia \\ 2D3 Teknologi Telekomunikasi Universitas Telkom, Indonesia \\ Email: risnandasatriatama@student.telkomuniversity.ac.id
}

Received 10 Februari 2020 | Revised 2 April 2020 | Accepted 16 April 2020

\begin{abstract}
ABSTRAK
Troli rotari memerlukan sistem kontrol untuk mengatur rak ke posisi yang diinginkan. Penelitian ini berfokus pada sistem kontrol posisi rak menggunakan metode Fuzzy Logic Controller (FLC) dengan beban berbeda dari setiap pengguna. Masukan pada sistem kontrol FLC adalah error dan delta error dari sensor rotary encoder. Keluaran dari FLC adalah Pulse Width Modulation yang digunakan untuk mengontrol kecepatan motor DC. Hasil penelitian dari tiga variasi fungsi keanggotaan keluaran dengan beban pada satu rak, pengujian tanpa beban memiliki settling time antara 3,11 s hingga 3,24 s dan error steady state antara 3 hingga 8 counter. Pengujian dengan beban $250 \mathrm{~g}$ memiliki settling time antara 3,92 s hingga 8,80 s dan error steady state antara -5 counter hingga 4 counter. Sedangkan pengujian dengan beban $500 \mathrm{~g}$ memiliki settling time antara 4,66 s hingga 7,39 s dan error steady state antara 8 counter hingga 12 counter.
\end{abstract}

Kata kunci: tempat penitipan barang, troli rotari, Fuzzy Logic Controller.

\begin{abstract}
Rotary trolley needs control system that used for rack control to the position. The research focused on rack position control system using the Fuzzy Logic Controller (FLC) method with different loads from each user. Inputs to the FLC control system are error and delta error from the rotary encoder sensor. The output of the FLC is Pulse Width Modulation which is used to control the speed of the DC motor. The results from 3 variations of the meeting results, the no-load test had a completion time of between $3.11 \mathrm{~s}$ to $3.24 \mathrm{~s}$ and steady-state conditions between 3 counters to 8 counters. Testing with a load of $250 \mathrm{~g}$ has a completion time of $3.92 \mathrm{~s}$ to 8.80 $s$ and steady-state conditions between -5 counters to 4 counters. While testing with a load of $500 \mathrm{~g}$ has a settling time of $4.66 \mathrm{~s}$ to $7.39 \mathrm{~s}$ and steady-state conditions between 8 to 12 counters.
\end{abstract}

Keywords: deposit box, rotary trolley, Fuzzy Logic Controller. 


\section{PENDAHULUAN}

Pada umumnya di tempat seperti pusat perbelanjaan, perpustakaan, dan lainnya terdapat fasilitas tempat penitipan barang. Tempat penitipan barang bertujuan untuk mencegah pencurian oleh pengunjung dan meningkatkan kenyamanan pengunjung agar tidak kerepotan membawa barang-barangnya. Akan tetapi pada waktu tertentu, tempat penitipan barang tidak memiliki cukup ruang karena pengunjung yang cukup banyak. Selain itu, keamanan pada tempat penitipan barang konvensional masih terbilang rentan karena hanya menggunakan rak terbuka (Al Masyhur, 2015). Hal ini disebabkan karena rak terbuka tidak memiliki penutup, sehingga masih rawan terhadap pencurian walau dijaga oleh petugas operasional. Solusi untuk mengatasi kedua masalah tersebut yaitu dengan mengadopsi parkir rotasi untuk tempat penitipan barang dengan akses dari RFID.

Parkir rotasi dapat menghemat penggunaan ruang hingga enam kali lipat bahkan lebih, tergantung pada konstruksi yang dibuat (Patel, dkk, 2015). Hal ini karena prinsip parkir rotasi yang menggunakan ruang vertikal dan mengandalkan putaran rotasi untuk sistem pergerakannya. Prinsip yang sama digunakan juga pada sistem lift cerdas (Malau, dkk, 2011). Terdapat dua faktor yang menjadi pendorong terciptanya konsep sistem parkir otomatis ini, yaitu kebutuhan akan ruang parkir dan kelangkaan pada lahan yang tersedia (Mohamed, dkk, 2016). Sejauh ini, parkir rotasi baru diterapkan pada tempat parkir mobil. Sehingga penerapan konsep ini pada tempat penitipan barang merupakan solusi yang tepat untuk menghemat penggunaan lahan. Pada implementasinya, konstruksi rak penitipan barang dapat dibuat hingga mencapai langit-langit atau plafon ruangan. Sehingga jumlah rak penitipan barang pun dapat lebih banyak. Karena konsep parkir rotasi akan diterapkan pada tempat penitipan barang, maka alat tersebut dinamakan troli rotari.

Troli rotari membutuhkan sistem kontrol untuk mengatur rak ke posisi yang ditentukan. Sejauh ini, metode kontrol konvensional yang digunakan pada konsep ini yaitu Kontrol ProportionalIntegral-Derivative (PID) dan Fuzzy Logic Controller (FLC). Kontrol PID membutuhkan model matematika, sedangkan FLC berbasis pada pengalaman menggunakan rules (Almatheel \& Abdelrahman, 2017). (Putra, dkk, 2013) menerapkan metode PID kontroler pada sistem parkir rotasi pada tahun 2013. Sedangkan pada tahun 2018, (Ismail, dkk, 2018) menerapkan metode FLC pada sistem ini. Akan tetapi penelitian tersebut tidak memperhatikan variabel beban setiap rak dari sistem tersebut. Sedangkan barang yang akan dititipkan oleh setiap pengguna pada sistem ini diasumsikan memiliki beban yang berbeda. Oleh karena itu diperlukan pengembangan sistem kontrol untuk mengatur posisi rak ketika terdapat perbedaan beban pada setiap rak. Maka dari itu digunakan metode FLC.

FLC digunakan karena memiliki sifat yang dinamis seperti pola pikir manusia. Konsep FLC mudah dimengerti, fleksibel, dan dapat memodelkan fungsi non linier (Wida, 2012). Metode ini diharapkan dapat memberikan respon yang baik untuk mengatur rak dengan beban berbeda yang tanpa menggunakan sensor pengukur beban pada alat ini. Indikator atau parameter masukan pada FLC yang dapat merepresentasikan resultan gaya berat total yang bekerja pada sistem akan dibahas lebih lanjut. Metode FLC juga banyak diimplementasikan pada sistem robotika (Nugraha, dkk, 2015) atau sistem kontrol mekanika lainnya seperti pada sistem pelacak matahari (Pangaribuan \& Darlis, 2018). Selain itu metode ini juga telah banyak digunakan di industri karena dianggap lebih optimal dibandingkan dengan sistem kontrol biasa.

Selain itu untuk meningkatkan keamanan, sistem akses pada troli rotari menggunakan RFID. Adapun hanya terdapat 1 pintu yang akan menjadi akses barang keluar dan masuk. Sesuai 
dengan algoritma yang akan dirancang, nomor rak dengan barang tertentu hanya dapat diakses oleh RFID yang telah ditandai pada nomor rak tersebut.

\section{METODOLOGI DAN PERANCANGAN SISTEM}

\subsection{Tempat Penitipan Barang}

Terdapat 2 jenis tempat penitipan barang, contohnya dapat dilihat pada Gambar 1.

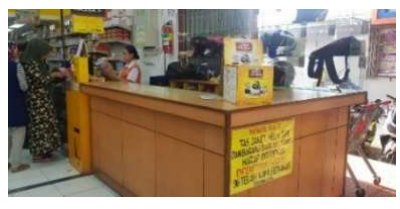

(a)

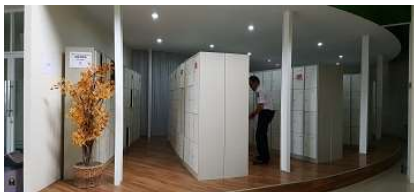

(b)

Gambar 1. (a) Tempat Penitipan Barang Konvensional, (b) Tempat Penitipan Barang dengan Pengunci (Open Library Universitas Telkom, 2017)

Tempat penitipan barang yang menjadi acuan latar belakang masalah penelitian ini yaitu tempat penitipan barang konvensional yang dapat ditunjukkan oleh Gambar 1(a). Hasil survei yang dilakukan di tiga tempat yang memiliki fasilitas tempat penitipan barang konvensional di Kota/Kab Bandung dapat ditunjukkan oleh Tabel 1.

Tabel 1. Hasil Survei Ukuran Tempat Penitipan Barang di Kota Bandung

\begin{tabular}{|c|c|c|c|c|c|c|}
\hline No. & $P_{\text {Rak }}(\mathrm{cm})$ & $\mathrm{L}_{\text {Rak }}(\mathrm{cm})$ & $T_{\text {Rak }}(\mathrm{cm})$ & $\begin{array}{l}\text { P }_{\text {Fasilitas }} \\
\text { (m) }\end{array}$ & $\begin{array}{l}\text { LFasilitas } \\
\text { (m) }\end{array}$ & $\begin{array}{c}\text { Total Ruang Pada } \\
\text { Rak }\end{array}$ \\
\hline 1 & 37 & 35 & 35 & 2,1 & 1,65 & 37 \\
\hline 2 & 35 & 32.5 & 33 & 3 & 2,4 & 36 \\
\hline 3 & 35.5 & 32 & 32 & 1 & 2,5 & 21 \\
\hline
\end{tabular}

Berdasarkan Tabel 1 tersebut, rata-rata ukuran tempat penitipan barang dari tiga data yang diperoleh adalah 2,03 x 1,85 m dan rata-rata memiliki 31 ruang. Adapun rata-rata dimensi dari tiga data yang diperoleh yaitu $35,83 \times 33,16 \times 33,3 \mathrm{~cm}$. Jadi alat yang akan dibuat berbanding 1:4 dengan rata-rata dimensi dari data yang diperoleh yaitu $8,96 \times 8,29 \times 8,32 \mathrm{~cm}$. Berdasarkan kondisi tersebut, penggunaan ruang fasilitas dapat lebih hemat dengan sistem parkir rotasi yang diterapkan pada tempat penitipan barang.

\subsection{Rotary Parking dan Troli Rotari}

Rotary parking atau parkir rotasi adalah salah satu sistem parkir pintar yang berotasi pada sumbu vertikal (Nurega, dkk, 2016). Sistem parkir jenis ini dapat menampung dua buah kendaraan secara horizontal dan beberapa kendaraan secara vertikal tergantung tinggi dari konstruksi mekaniknya. Ilustrasi sistem parkir rotasi ditunjukkan oleh Gambar 2.

Penerapan konsep parkir rotasi pada tempat penitipan barang disebut troli rotari. Jika sebelumnya diperlukan petugas operasional pada tempat penitipan barang, penerapan konsep ini dapat menjadi otomatis tanpa petugas operasional. Selain itu penggunaannya lebih aman karena satu rak hanya dapat diakses oleh satu kartu RFID yang telah ditandai pada nomor rak tersebut. 


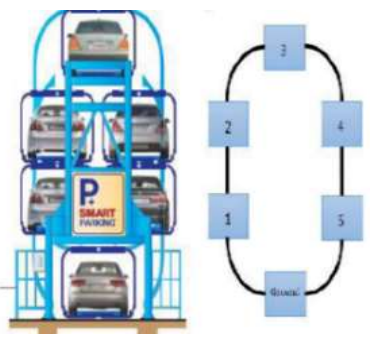

Gambar 2. Ilustrasi Parkir Rotari (Sodiq \& Hasbullah, 2017)

\subsection{Perancangan Fuzzy Logic Controller (FLC)}

Himpunan fuzzy memiliki derajat keanggotaan dari 0 hingga 1 (Kusumadewi \& Hartati, 2010). Daerah 0 hingga 1 ini yang disebut samar (fuzzy), berbeda dengan logika digital yang hanya memiliki dua derajat keanggotaan yaitu 0 dan 1 . Daerah samar tersebut dapat merepresentasikan nilai yang bersifat linguistik seperti dekat, sangat dekat, dsb (Rizki, dkk, 2018). FLC digunakan untuk mengatur posisi suatu rak ke posisi yang diinginkan. Adapun parameter masukan yang digunakan pada FLC adalah error (e) posisi dan delta error $(\Delta \mathrm{e})$ posisi yang diperoleh dari sensor rotary encoder. Parameter masukan FLC tersebut dapat dilihat pada diagram blok kontrol posisi yang ditunjukkan oleh Gambar 3 berikut.

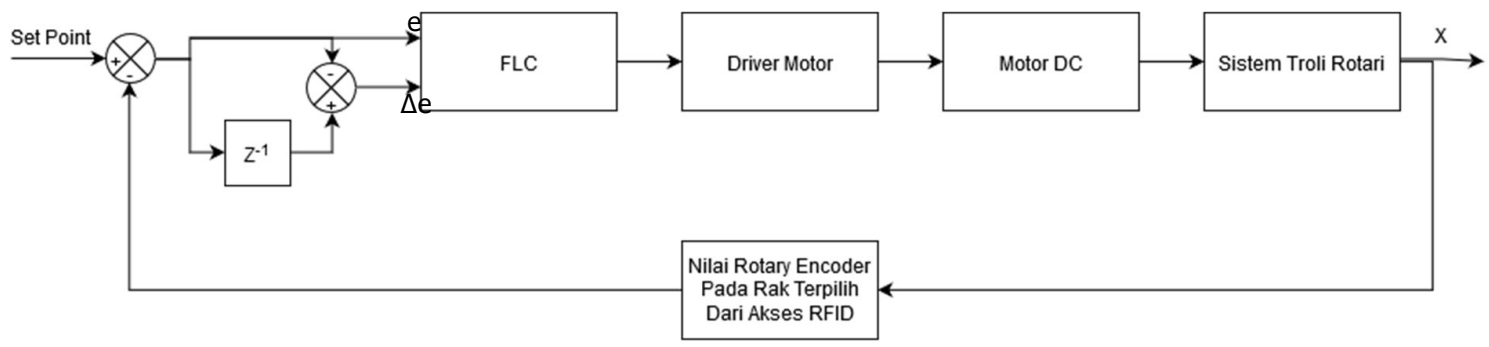

Gambar 3. Diagram Blok Kontrol Posisi

Error (e) posisi direpresentasikan oleh selisih nilai rotary encoderpada rak terkait terhadap set point. Sedangkan delta error $(\Delta \mathrm{e})$ posisi direpresentasikan oleh selisih antara error (e) posisi saat ini dan error (e) posisi sebelumnya. Dalam hal ini, secara tidak langsung delta error $(\Delta \mathrm{e})$ dapat merepresentasikan resultan gaya berat total yang bekerja pada sistem tersebut. Jadi ketika beban pada setiap rak berubah, beban dapat diketahui hanya dari sensor rotary encoder tanpa menggunakan sensor pengukur beban. Adapun nilai sensor rotary encoder dan perencanaan pergerakan kinematika sistem dapat diilustrasikan pada Gambar 4.

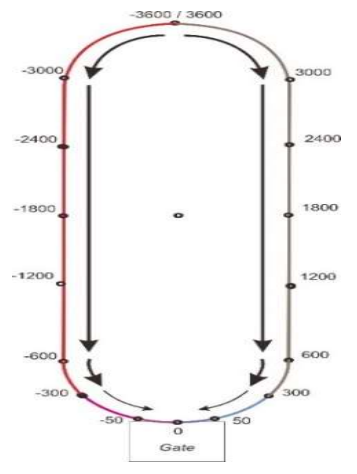

Gambar 4. Ilustrasi Perencanaan Kinematika Sistem 
Dari perencanaan sistem tersebut, dibuat fungsi keanggotaan masukan error (e) posisi dan delta error $(\Delta \mathrm{e})$ posisi yang ditunjukkan oleh Gambar 5.

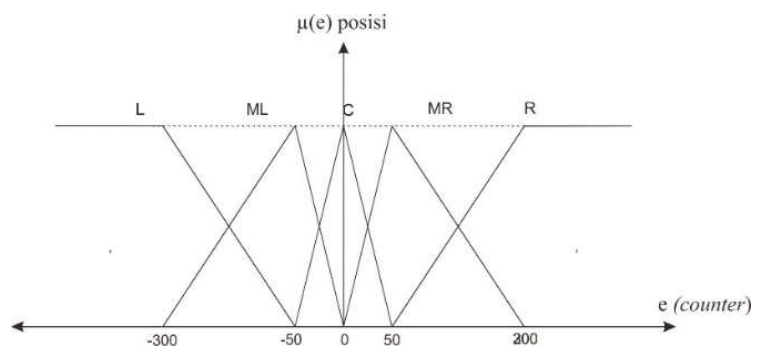

(a)

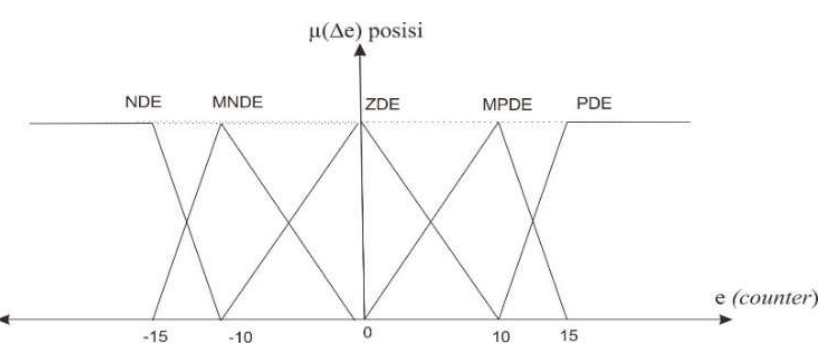

(b)

\section{Gambar 5. (a) Himpunan Fungsi Keanggotaan Masukan Error (e) Posisi, (b) Himpunan Fungsi Keanggotaan Masukan Delta Error $(\Delta \mathrm{e})$ Posisi}

Berdasarkan Gambar 5, terdapat lima fungsi keanggotaan pada masukan error (e) posisi dan masukan delta error $(\Delta \mathrm{e})$ posisi. Fungsi keanggotaan pada masukan error (e) posisi yaitu left $(\mathrm{L})$, most left $(\mathrm{ML})$, center $(\mathrm{C})$, most right $(\mathrm{MR})$, dan right $(\mathrm{R})$. Sedangkan fungsi keanggotaan pada masukan delta error (e) posisi yaitu Negative Delta Error(NDE), Medium Negative Delta Error(MNDE), Zero Delta Error(ZDE), Medium Positive Delta Error(MPDE) dan Positive Delta Error (PDE). Setelah menentukan himpunan fungsi keanggotaan masukan. Tahap selanjutnya menentukan himpunan fungsi keanggotaan keluaran. Himpunan fungsi keanggotaan keluaran yang dirancang pada sistem ini dapat ditunjukkan oleh Gambar 6.

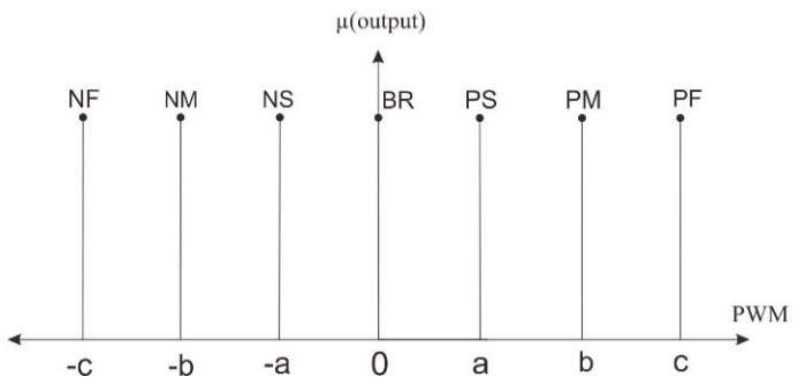

\section{Gambar 6. Himpunan Fungsi Keanggotaan Keluaran PWM}

Berdasarkan Gambar 6, terdapat 7 fungsi keanggotaan yaitu Negative Fast (NF), Negative Medium (NM), Negative Slow (NS), Brake (BR), Positive Slow (PS), Positive Medium (PM), dan Positive Fast (PF). Nilai keluaran PWM yaitu $-c,-b,-a, a, b$, dan c pada fungsi keanggotaan tersebut diperoleh dari metode trial and error yang akan dibahas lebih lanjut. Setelah menentukan fungsi keanggotaan keluaran. Tahap selanjutnya menentukan rules FLC. Rules FLC yang dirancang pada sistem ini dapat ditunjukkan oleh Tabel 2.

Tabel 2. Rules FLC

\begin{tabular}{|c|c|c|c|c|c|}
\hline $\mathbf{\Delta e}$ & $\mathbf{L}$ & $\mathbf{M L}$ & $\mathbf{C}$ & $\mathbf{M R}$ & $\mathbf{R}$ \\
\hline NDE & PM & PS & NS & NS & NM \\
\hline MNDE & NM & NS & NS & PS & PM \\
\hline ZDE & NF & NM & BR & PM & PF \\
\hline MPDE & NM & NS & PS & PS & PM \\
\hline PDE & PM & PS & PS & NS & NM \\
\hline
\end{tabular}


2.4 Perancangan Perangkat Keras

Desain perancangan perangkat keras dapat ditunjukkan oleh Gambar 7.

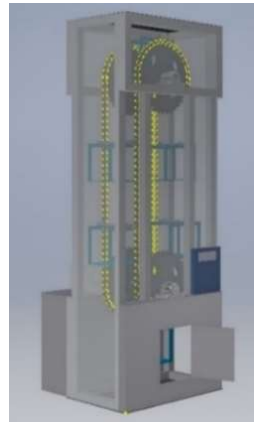

(a)

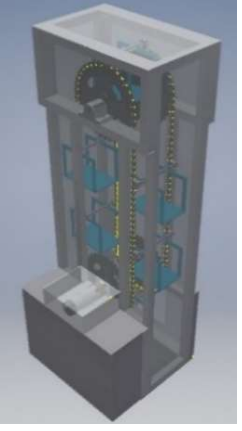

(b)

Gambar 7. (a) Desain Mekanik Tampak Kanan Depan, (b) Desain Mekanik Tampak Kanan Belakang

Berdasarkan Gambar 7, setiap rak digantung pada sebuah silinder yang terhubung pada dua rantai dan roda gigi. Roda gigi juga terhubung pada motor DC dan sensor rotary encoder. Motor DC akan menggerakkan posisi rak menggunakan mekanisme roda gigi dan rantai yang terhubung pada rak. Alat yang telah direalisasikan dapat ditunjukkan oleh Gambar 8.

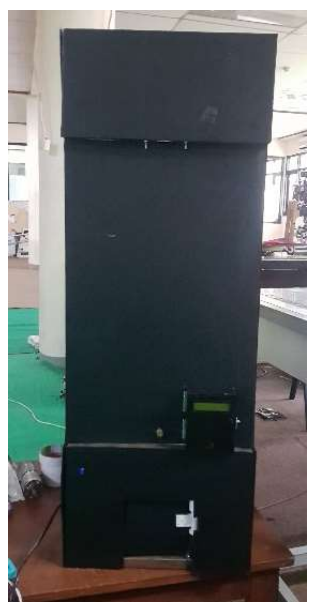

(a)

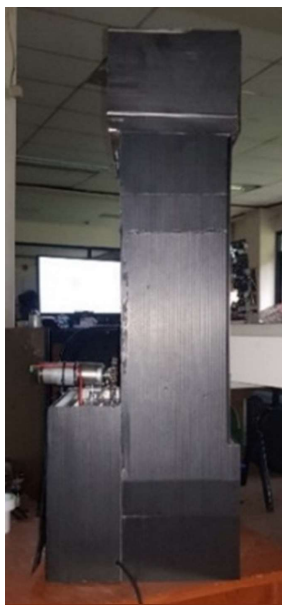

(b)

Gambar 8. (a) Realisasi Alat Tampak Kanan Depan, (b) Realisasi Alat Tampak Kanan Samping

\section{HASIL DAN PEMBAHASAN}

\subsection{Pengujian FLC Pada Sistem}

Pengujian FLC pada sistem ini meliputi pengujian FLC dengan tiga variasi fungsi keanggotaan keluaran pada satu rak, serta pengujian FLC dengan beban yang berbeda pada dua rak, tiga rak, dan enam rak. Beban dalam pengujian ini yaitu $0 \mathrm{~g}, 250 \mathrm{~g}$, dan $500 \mathrm{~g}$.

\subsubsection{Pengujian FLC Dengan Beban Berbeda pada Satu Rak}

Pengujian FLC dengan beban berbeda pada satu rak meliputi tiga variasi fungsi keanggotaan keluaran. Tiga variasi fungsi keanggotaan keluaran diperoleh dengan metode trial and error. Setelah ditetapkan tiga variasi fungsi keanggotaan keluaran, dilakukan pengujian FLC untuk 
mengatur posisi rak nomor 3 pada set point. Posisi rak nomor 3 saat pengujian dimulai berada pada posisi 1800 counter. Sedangkan rak nomor 0 yang diisi beban yang berbeda berada pada posisi set point atau pada posisi 5400 counter. Ilustrasi penempatan beban berbeda pada rak nomor 0 dapat ditunjukkan oleh Gambar 9.

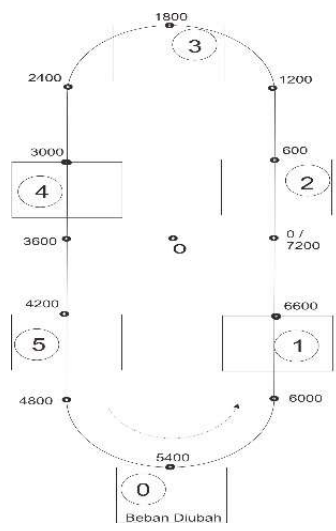

Gambar 9. Ilustrasi Beban pada Satu Rak

Adapun tiga variasi fungsi keanggotaan keluaran yang telah ditentukan dapat ditunjukkan oleh Gambar 10.

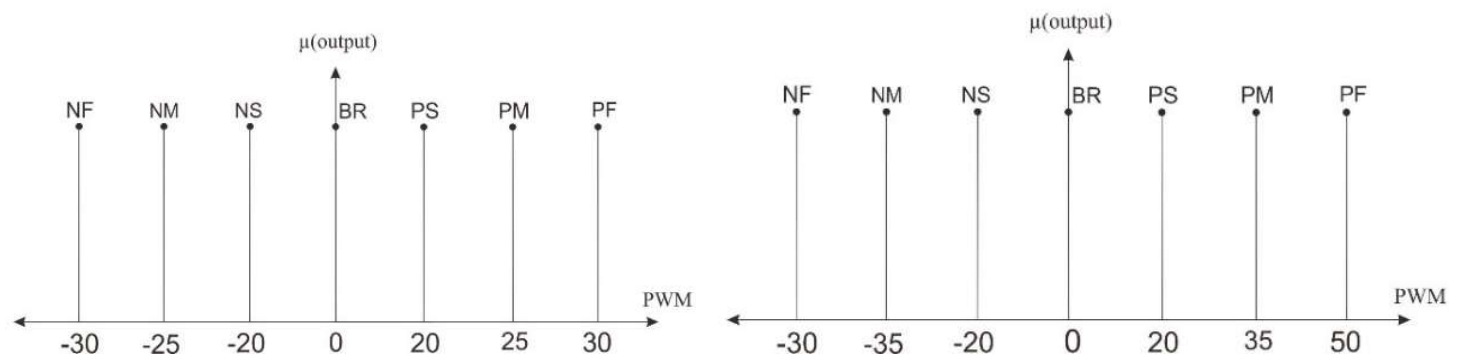

(a)

(b)

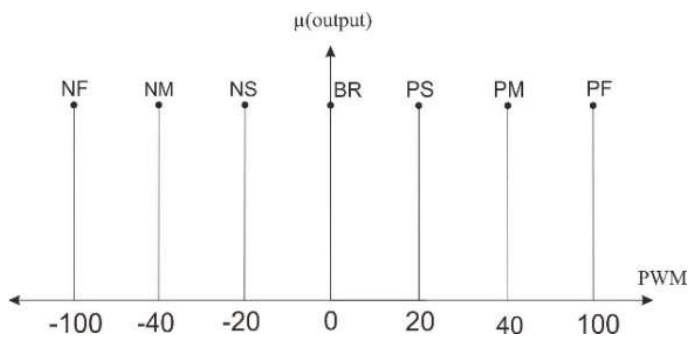

(c)

Gambar 10. (a) Fungsi Keanggotaan Keluaran Variasi 1, (b) Fungsi Keanggotaan Keluaran Variasi 2, (c) Fungsi Keanggotaan Keluaran Variasi 3

Setelah ditetapkan tiga variasi fungsi keanggotaan keluaran, dilakukan pengujian untuk memperoleh respon posisi. Adapun grafik respon posisi dari rak terhadap beban yang berbeda dapat ditunjukkan oleh Gambar 11. 


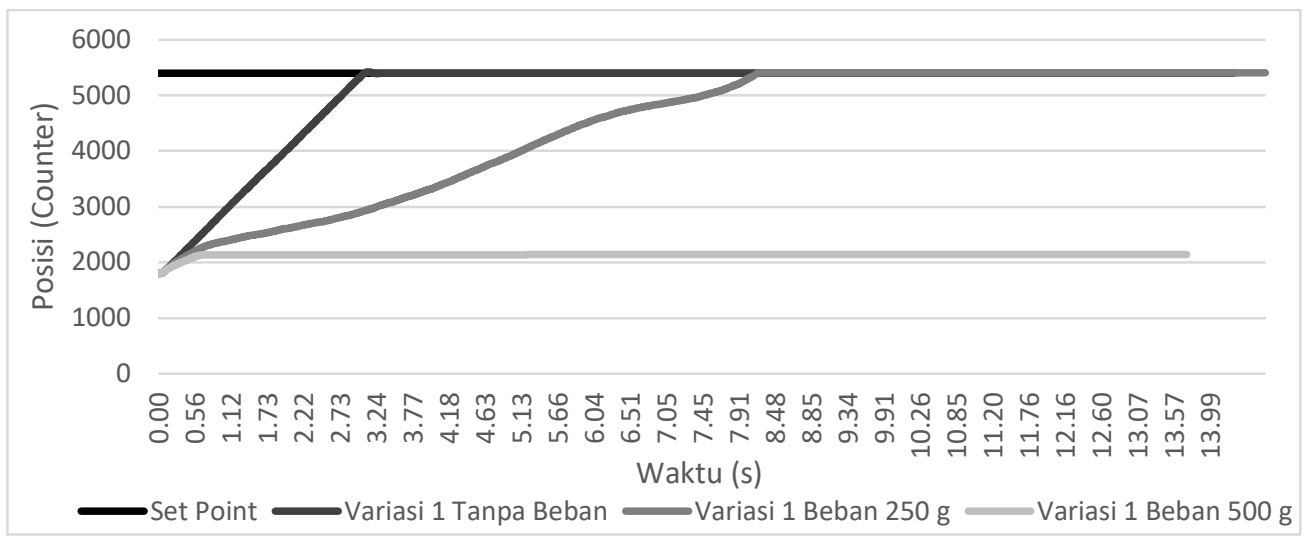

Gambar 11. Grafik Respon Posisi Fungsi Keanggotaan Keluaran Variasi 1 terhadap Beban Berbeda pada Rak Nomor 0

Berdasarkan hasil pengujian respon posisi seperti pada Gambar 11, diperoleh hasil analisis yang dapat ditunjukkan oleh Tabel 3 berikut.

Tabel 3. Hasil Pengujian Fungsi Keanggotaan Variasi 1 dengan Beban Berbeda pada Rak Nomor 0

\begin{tabular}{|c|c|c|c|c|c|}
\hline No. & $\begin{array}{c}\text { Beban } \\
(\mathbf{g})\end{array}$ & $\begin{array}{c}\text { Waktu } \\
\text { Mencapai Posisi } \\
\text { Tujuan (s) }\end{array}$ & $\begin{array}{c}\text { Waktu } \\
\text { Mencapai } \\
\text { Steady State (s) }\end{array}$ & $\begin{array}{c}\text { Error Steady } \\
\text { State } \\
\text { (counter) }\end{array}$ & $\begin{array}{c}\text { Maks. } \\
\text { Overshoot } \\
\text { (counter) }\end{array}$ \\
\hline 1 & 0 & 3,12 & 3,24 & 4 & 19 \\
\hline 2 & $250 \mathrm{~g}$ & 8,80 & 8,80 & -5 & 6 \\
\hline 3 & $500 \mathrm{~g}$ & - & - & 3291,00 & - \\
\hline
\end{tabular}

Berdasarkan hasil pengujian yang diperoleh, waktu tercepat untuk mencapai posisi tujuan dan mencapai steady state dihasilkan ketika pengujian tanpa beban yaitu 3,12 s dan 3,24 s. Error steady state terkecil pun dihasilkan ketika pengujian tanpa beban yaitu sebesar 4 counter. Posisi tujuan tidak tercapai pada pengujian dengan beban $500 \mathrm{~g}$. Hal ini disebabkan karena nilai maksimal PWM pada fungsi keanggotaan keluaran ini tidak dapat memutar motor DC dengan beban $500 \mathrm{~g}$. Adapun grafik respon posisi variasi 2 dapat ditunjukkan oleh Gambar 12.

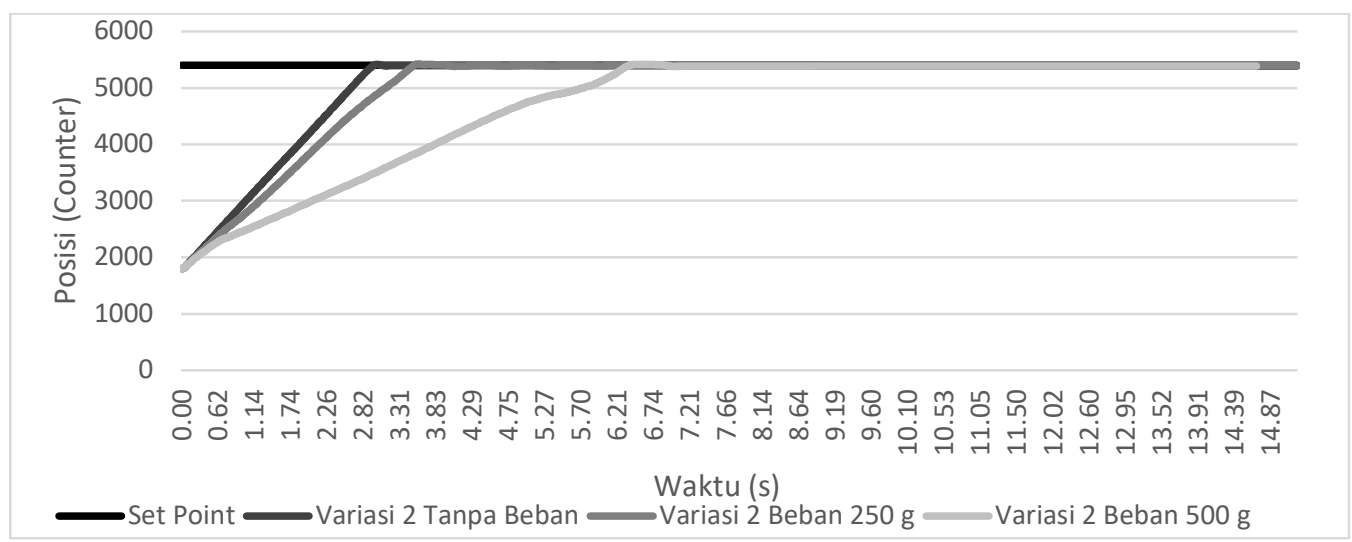

Gambar 12. Grafik Respon Posisi Fungsi Keanggotaan Keluaran Variasi 2 terhadap Beban Berbeda pada Rak Nomor 0 
Berdasarkan hasil pengujian respon posisi seperti pada Gambar 12, diperoleh hasil analisis yang dapat ditunjukkan oleh Tabel 4 berikut.

Tabel 4. Hasil Pengujian Fungsi Keanggotaan Variasi 2 dengan Beban Berbeda pada Rak Nomor 0

\begin{tabular}{|c|c|c|c|c|c|}
\hline No. & $\begin{array}{c}\text { Beban } \\
(\mathbf{g})\end{array}$ & $\begin{array}{c}\text { Waktu } \\
\text { Mencapai Posisi } \\
\text { Tujuan (s) }\end{array}$ & $\begin{array}{c}\text { Waktu } \\
\text { Mencapai } \\
\text { Steady State (s) }\end{array}$ & $\begin{array}{c}\text { Error Steady } \\
\text { State } \\
\text { (counter) }\end{array}$ & $\begin{array}{c}\text { Maks. } \\
\text { Overshoot } \\
\text { (counter) }\end{array}$ \\
\hline 1 & 0 & 3,01 & 3,11 & 8 & 19 \\
\hline 2 & $250 \mathrm{~g}$ & 3,61 & 3,92 & 4 & 24 \\
\hline 3 & $500 \mathrm{~g}$ & 6,72 & 7,39 & 12 & 15 \\
\hline
\end{tabular}

Berdasarkan hasil pengujian yang diperoleh, waktu tercepat untuk mencapai posisi yang ditentukan dihasilkan ketika pengujian tanpa beban yaitu 3,01 s. Waktu tercepat untuk mencapai steady state pun dihasilkan ketika pengujian tanpa beban yaitu 3,11 s. Akan tetapi, error steady state terkecil dihasilkan ketika pengujian dengan beban $250 \mathrm{~g}$ yaitu sebesar 4 counter. Adapun grafik respon posisi variasi 3 dapat ditunjukkan oleh Gambar 13.

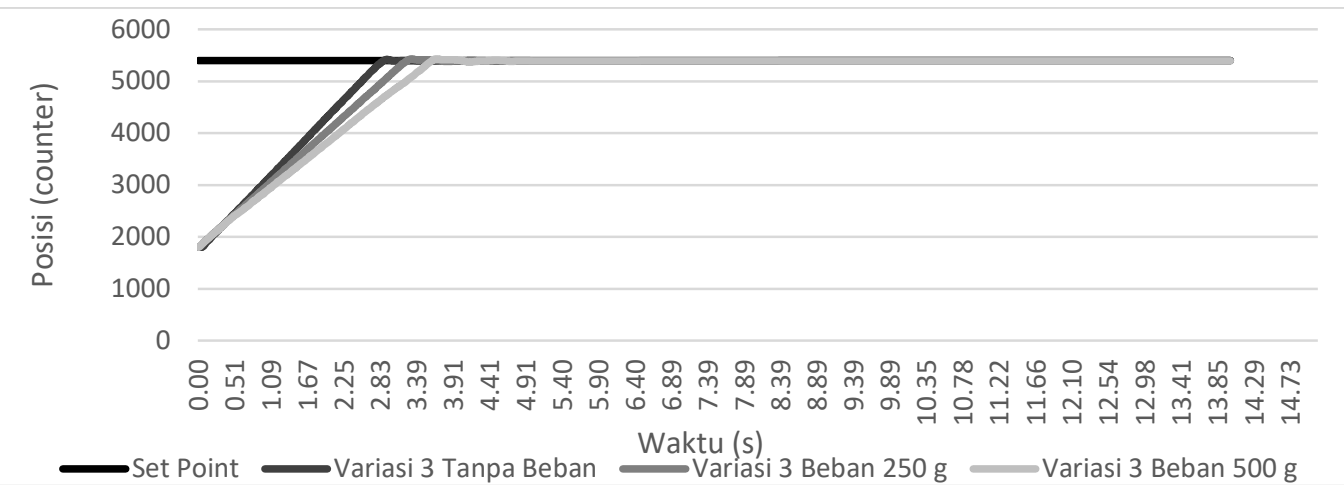

Gambar 13. Grafik Respon Posisi Fungsi Keanggotaan Keluaran Variasi 3 terhadap Beban Berbeda pada Rak Nomor 0

Berdasarkan hasil pengujian respon posisi seperti pada Gambar 13, diperoleh hasil analisis yang dapat ditunjukkan oleh Tabel 5.

Tabel 5. Hasil Pengujian Fungsi Keanggotaan Variasi 3 dengan Beban Berbeda pada Rak Nomor 0

\begin{tabular}{|c|c|c|c|c|c|}
\hline No. & $\begin{array}{c}\text { Beban } \\
(\mathbf{g})\end{array}$ & $\begin{array}{c}\text { Waktu } \\
\text { Mencapai Posisi } \\
\text { Tujuan (s) }\end{array}$ & $\begin{array}{c}\text { Waktu } \\
\text { Mencapai } \\
\text { Steady State (s) }\end{array}$ & $\begin{array}{c}\text { Error Steady } \\
\text { State } \\
\text { (counter) }\end{array}$ & $\begin{array}{c}\text { Maks. } \\
\text { Overshoot } \\
\text { (counter) }\end{array}$ \\
\hline 1 & 0 & 2,89 & 3,11 & 3 & 22 \\
\hline 2 & $250 \mathrm{~g}$ & 3,17 & 4,01 & 4 & 31 \\
\hline 3 & $500 \mathrm{~g}$ & 3,61 & 4,66 & 8 & 30 \\
\hline
\end{tabular}

Berdasarkan hasil pengujian yang diperoleh, waktu tercepat untuk mencapai posisi yang ditentukan dihasilkan ketika pengujian tanpa beban yaitu 2,89 s. Waktu tercepat untuk mencapai steady state dihasilkan ketika pengujian dengan beban $250 \mathrm{~g}$ yaitu 3,98 s. Akan tetapi, error steady state terkecil dihasilkan ketika pengujian tanpa beban yaitu sebesar -3 counter.

Dari hasil pengujian ketiga variasi fungsi keanggotaan keluaran FLC terhadap tiga variasi beban pada satu rak, fungsi keanggotaan keluaran FLC variasi 3 memiliki settling time yang 
paling mendekati. Maka dari itu fungsi keanggotaan keluaran FLC variasi 3 yang dapat dilihat pada Gambar 10 (c) akan digunakan untuk pengujian selanjutnya dengan parameter beban yang berbeda.

\subsubsection{Pengujian FLC Dengan Beban Berbeda pada Dua Rak}

Pengujian FLC pada dua rak dilakukan pada rak nomor 0 dan rak nomor 3 . Beban pada rak nomor 0 yaitu $250 \mathrm{~g}$. Sedangkan beban pada rak nomor 3 dibuat berbeda, yaitu $150 \mathrm{~g}, 250 \mathrm{~g}$, dan $350 \mathrm{~g}$. Rak nomor 0 berada pada posisi 1800 counter, sedangkan rak nomor 3 berada pada posisi 5400 counter atau pada set point. Adapun agar lebih jelas ilustrasi penempatan beban dapat ditunjukkan oleh Gambar 14.

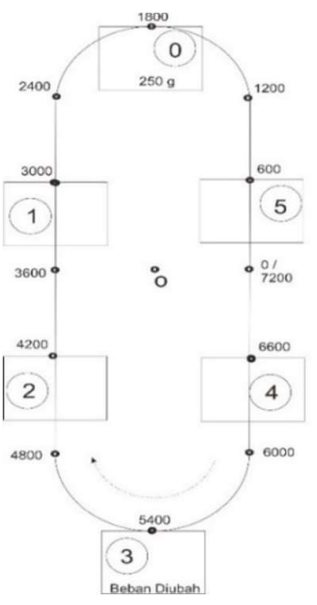

\section{Gambar 14. Ilustrasi Penempatan Beban Berbeda pada Rak Nomor 3}

Pada pengujian ini, posisi rak nomor 4 akan diatur menuju set point. Grafik respon posisi sistem terhadap beban yang berbeda pada rak nomor 3 dapat ditunjukkan oleh Gambar 15.

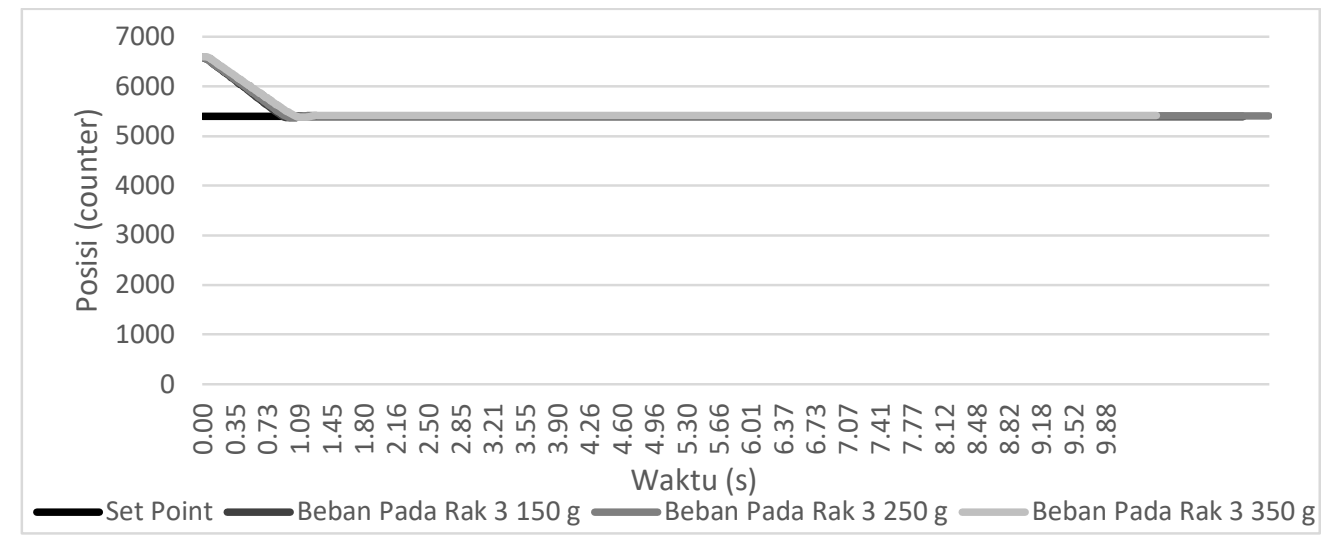

Gambar 15. Grafik Respon Posisi dengan Beban Berbeda pada Rak Nomor 3

Berdasarkan hasil pengujian respon posisi seperti pada Gambar 15, diperoleh hasil analisis yang dapat ditunjukkan oleh Tabel 6 berikut. 
Sistem Kontrol Troli Rotari sebagai Tempat Penitipan Barang Otomatis menggunakan

Fuzzy Logic

Tabel 6. Hasil Pengujian FLC dengan Beban Berbeda pada Rak Nomor 3

\begin{tabular}{|c|c|c|c|c|c|}
\hline No. & $\begin{array}{c}\text { Beban Pada } \\
\text { Rak 3 (g) }\end{array}$ & $\begin{array}{c}\text { Waktu } \\
\text { Mencapai Posisi } \\
\text { Tujuan (s) }\end{array}$ & $\begin{array}{c}\text { Waktu } \\
\text { Mencapai } \\
\text { Steady State (s) }\end{array}$ & $\begin{array}{c}\text { Error Steady } \\
\text { State } \\
\text { (counter) }\end{array}$ & $\begin{array}{c}\text { Maks. } \\
\text { Overshoot } \\
\text { (counter) }\end{array}$ \\
\hline 1 & 150 & 0,91 & 1,20 & 11 & 27 \\
\hline 2 & 250 & 0,94 & 1,45 & -6 & 32 \\
\hline 3 & 350 & 1,07 & 1,41 & -14 & 19 \\
\hline
\end{tabular}

Berdasarkan hasil pengujian yang diperoleh, waktu tercepat untuk mencapai posisi yang ditentukan dihasilkan ketika pengujian dengan beban $150 \mathrm{~g}$ pada rak nomor 3, dengan waktu $0,91 \mathrm{~s}$. Waktu tercepat untuk mencapai steady state juga dihasilkan ketika pengujian dengan beban $150 \mathrm{~g}$ pada rak 3 yaitu 3,98 s. Akan tetapi, error steady state terkecil dihasilkan ketika pengujian dengan beban $250 \mathrm{~g}$, yaitu sebesar -6 counter. Dari data dan grafik tersebut, disimpulkan bahwa FLC dapat mengatur posisi saat beban berbeda pada dua rak. Walaupun terdapat perbedaan waktu mencapai set point pada pengujian tersebut, perbedaan waktu tersebut tidak terlalu signifikan.

\subsubsection{Pengujian FLC dengan Beban Berbeda pada Tiga Rak}

Adapun Pengujian FLC pada tiga rak dilakukan pada rak nomor 0, rak nomor 3, dan rak nomor 4. Beban pada rak nomor 0 yaitu $250 \mathrm{~g}$ dan beban pada rak nomor 3 dan $150 \mathrm{~g}$. Sedangkan beban rak nomor 4 dibuat berbeda, yaitu $150 \mathrm{~g}, 250 \mathrm{~g}$, dan $350 \mathrm{~g}$. Rak nomor 0 berada pada posisi 600 counter, rak nomor 3 berada pada posisi 4200 counter, sedangkan rak nomor 4 berada pada posisi 5400 counter atau pada set point. Adapun agar lebih jelas ilustrasi penempatan beban dapat ditunjukkan oleh Gambar 16.

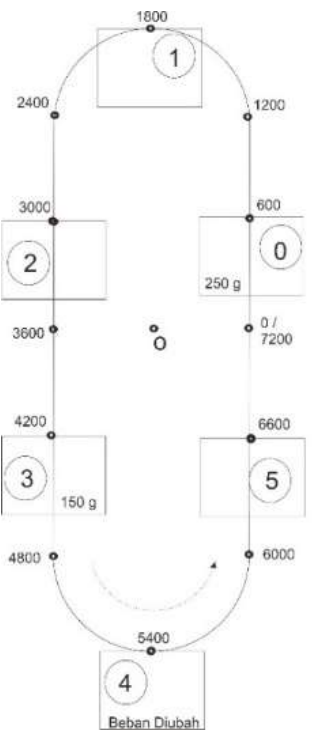

Gambar 16. Ilustrasi Penempatan Beban Berbeda pada Rak Nomor 4 
Pada pengujian ini, posisi rak nomor 1 akan diatur menuju set point. Grafik respon posisi sistem terhadap beban yang berbeda pada rak nomor 4 dapat ditunjukkan oleh Gambar 17.

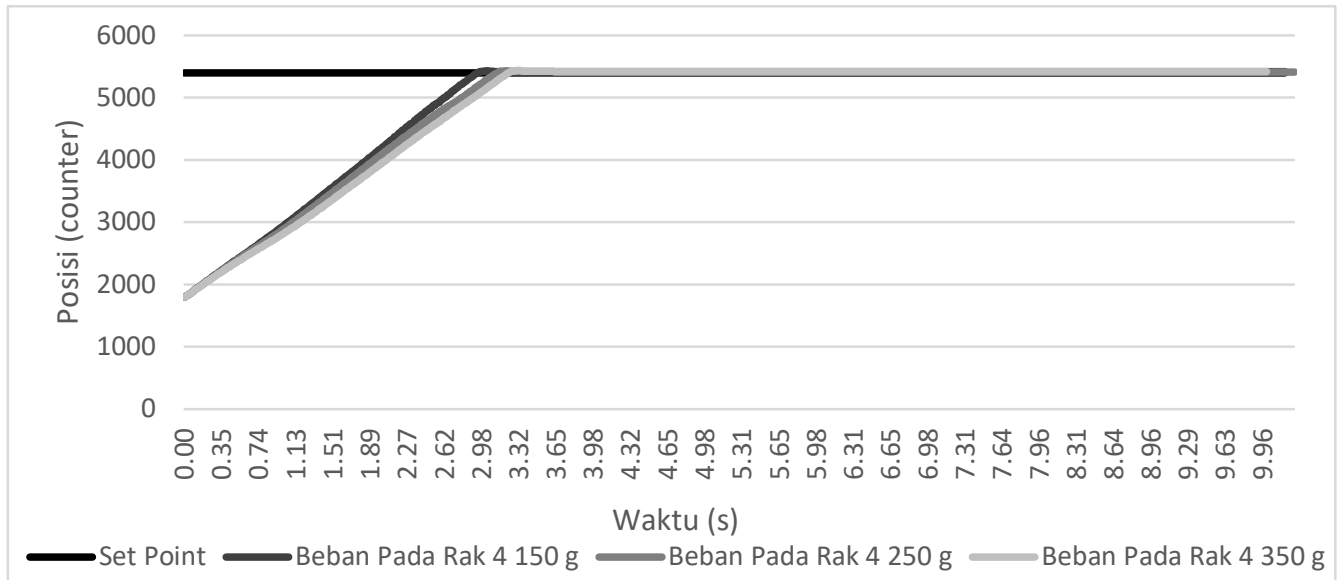

Gambar 17. Respon Posisi dengan Beban Berbeda pada Rak Nomor 4

Berdasarkan hasil pengujian respon posisi seperti pada Gambar 17, diperoleh hasil analisis yang dapat ditunjukkan oleh Tabel 7 berikut.

Tabel 7. Hasil Pengujian FLC dengan Beban Berbeda pada Rak Nomor 4

\begin{tabular}{|c|c|c|c|c|c|}
\hline No. & $\begin{array}{c}\text { Beban Pada } \\
\text { Rak 4 (g) }\end{array}$ & $\begin{array}{c}\text { Waktu } \\
\text { Mencapai Posisi } \\
\text { Tujuan (s) }\end{array}$ & $\begin{array}{c}\text { Waktu } \\
\text { Mencapai } \\
\text { Steady State (s) }\end{array}$ & $\begin{array}{c}\text { Error Steady } \\
\text { State } \\
\text { (counter) }\end{array}$ & $\begin{array}{c}\text { Maks. } \\
\text { overshoot } \\
\text { (counter) }\end{array}$ \\
\hline 1 & 150 & 2,96 & 3,11 & -18 & 31 \\
\hline 2 & 250 & 3,19 & 3,73 & -12 & 30 \\
\hline 3 & 350 & 3,32 & 4,27 & -14 & 41 \\
\hline
\end{tabular}

Berdasarkan hasil pengujian yang diperoleh, waktu tercepat untuk mencapai posisi yang ditentukan dihasilkan ketika pengujian dengan beban $150 \mathrm{~g}$ pada rak 4, dengan waktu 2,96 s. Waktu tercepat untuk mencapai steady state juga dihasilkan ketika pengujian dengan beban $150 \mathrm{~g}$ pada rak 4 yaitu 3,11 s. Akan tetapi, error steady state terkecil dihasilkan ketika pengujian dengan beban $250 \mathrm{~g}$, yaitu sebesar -2 counter. Walaupun terdapat perbedaan waktu mencapai set point pada pengujian tersebut, perbedaan waktu tersebut tidak terlalu jauh.

\subsubsection{Pengujian FLC dengan Beban Berbeda pada Enam Rak}

Adapun Pengujian FLC pada enam rak dilakukan pada seluruh rak. Beban pada rak nomor 0 yaitu $350 \mathrm{~g}$, beban pada rak nomor 1 yaitu $400 \mathrm{~g}$, beban pada rak nomor 3 yaitu $150 \mathrm{~g}$, beban pada rak nomor 4 yaitu $650 \mathrm{~g}$, dan beban pada rak nomor 5 yaitu $50 \mathrm{~g}$. Sedangkan beban rak nomor 2 dibuat berbeda, yaitu $350 \mathrm{~g}, 450 \mathrm{~g}$, dan $500 \mathrm{~g}$. Untuk saat ini rak nomor 2 berada pada posisi 1800 counterdan akan dikontrol menuju set point. Adapun agar lebih jelas ilustrasi penempatan beban dapat ditunjukkan oleh Gambar 18. 
Sistem Kontrol Troli Rotari sebagai Tempat Penitipan Barang Otomatis menggunakan Fuzzy Logic

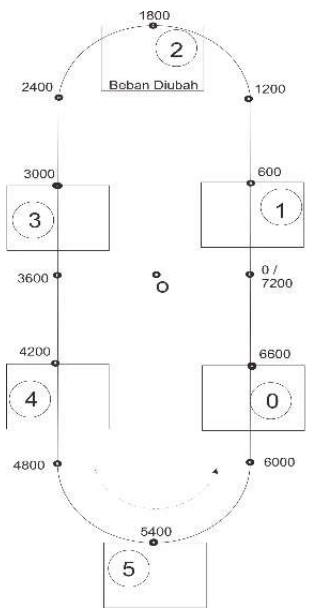

Gambar 18. Ilustrasi Penempatan Beban Berbeda pada Rak Nomor 2

Pada pengujian ini, posisi rak nomor 2 dengan beban yang berbeda akan diatur menuju set point. Grafik respon posisi sistem dapat ditunjukkan oleh Gambar 19.

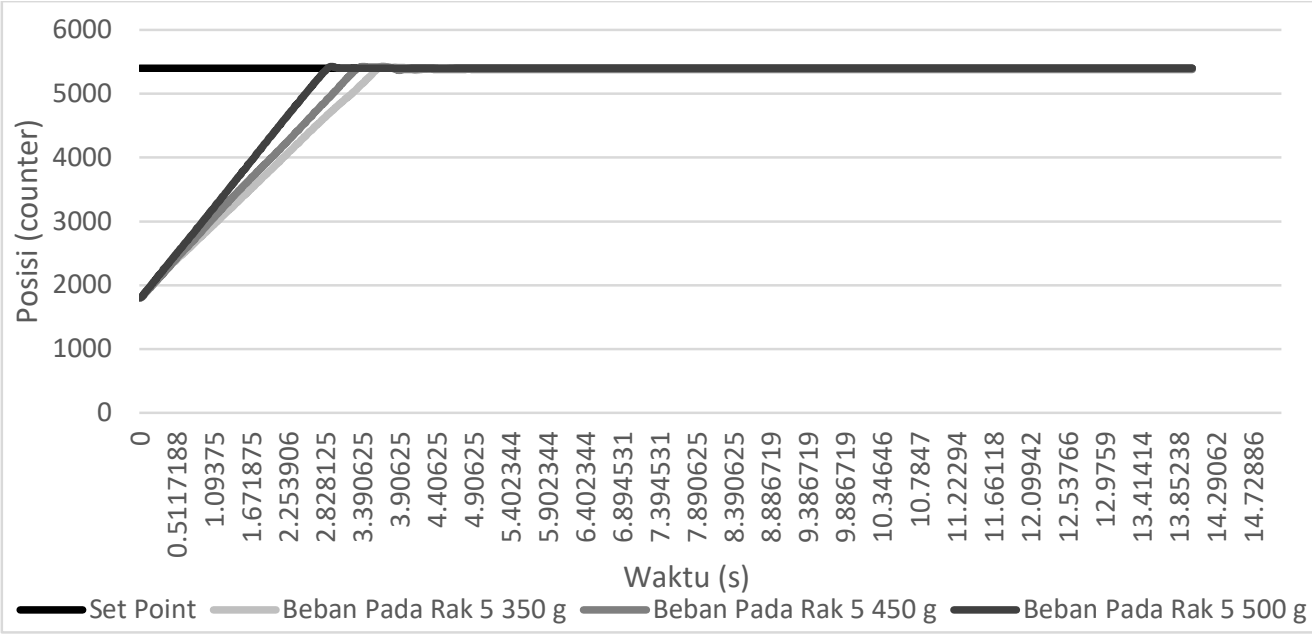

Gambar 19. Respon Posisi dengan Beban Berbeda pada Rak Nomor 2

Berdasarkan hasil pengujian respon posisi seperti pada Gambar 19, diperoleh hasil analisis yang dapat ditunjukkan oleh Tabel 8 berikut.

Tabel 8. Hasil Pengujian FLC dengan Beban Berbeda pada Rak Nomor 2

\begin{tabular}{|c|c|c|c|c|c|}
\hline No. & $\begin{array}{c}\text { Beban Pada } \\
\text { Rak 4 (g) }\end{array}$ & $\begin{array}{c}\text { Waktu } \\
\text { Mencapai Posisi } \\
\text { Tujuan (s) }\end{array}$ & $\begin{array}{c}\text { Waktu } \\
\text { Mencapai } \\
\text { Steady State (s) }\end{array}$ & $\begin{array}{c}\text { Error Steady } \\
\text { State } \\
\text { (counter) }\end{array}$ & $\begin{array}{c}\text { Maks. } \\
\text { Overshoot } \\
\text { (counter) }\end{array}$ \\
\hline 1 & $350 \mathrm{~g}$ & 3,44 & 3,88 & -3 & 29 \\
\hline 2 & $450 \mathrm{~g}$ & 3,09 & 3,41 & -2 & 33 \\
\hline 3 & $500 \mathrm{~g}$ & 2,76 & 2,89 & 6 & 37 \\
\hline
\end{tabular}

Berdasarkan hasil pengujian yang diperoleh, waktu tercepat untuk mencapai posisi yang ditentukan dihasilkan ketika pengujian dengan beban paling tinggi yaitu $500 \mathrm{~g}$ pada rak 2, dengan waktu 2,76 s. Hal ini disebabkan resultan gaya pada sistem mendominasi sebelah kiri dan aktuator berputar secara Counter Clock Wise (CCW), kemudian secara tidak langsung 
menimbulkan gaya berat ke bawah akibat gravitasi. Maka ketika beban pada rak terkait semakin tinggi, waktu mencapai posisi tujuan juga semakin cepat. Waktu tercepat untuk mencapai steady state juga dihasilkan ketika pengujian dengan beban $500 \mathrm{~g}$ pada rak 2 yaitu 2,89 s. Akan tetapi, error steady state terkecil dihasilkan ketika pengujian dengan beban 450 g, yaitu sebesar -2 counter. Walaupun terdapat perbedaan waktu mencapai set point pada pengujian tersebut, perbedaan waktu tersebut tidak signifikan atau tidak terlalu lama.

\subsection{Pengujian Algoritma Sistem}

Pengujian algoritma alat meliputi pengujian algoritma penentuan ruang dan akses RFID. Pengujian algoritma alat bertujuan untuk mengetahui bahwa algoritma penentuan ruang sudah benar. Adapun pengujian ini bertujuan agar mengetahui bahwa akses sebuah RFID hanya untuk satu rak. Pengujian dilakukan dengan cara menampilkan status dari RFID (menitip/mengambil) pada serial monitor di arduino. Untuk nomor rak yang diatur ke set point dilihat berdasarkan nomor pada rak ketika gate atau pintu terbuka dan dibandingkan dengan algoritma alat. Pengujian algoritma alat dapat ditunjukkan oleh Tabel 9 berikut.

Tabel 9. Pengujian Algoritma Alat

\begin{tabular}{|c|c|c|c|c|c|}
\hline No. & $\begin{array}{c}\text { Kartu } \\
\text { RFID yang } \\
\text { ditapping }\end{array}$ & $\begin{array}{c}\text { Kondisi Status } \\
\text { (Titip/Ambil) } \\
\text { Pada Serial } \\
\text { Monitor }\end{array}$ & $\begin{array}{c}\text { Kondisi Status } \\
\text { (Titip/Ambil) } \\
\text { Seharusnya }\end{array}$ & $\begin{array}{c}\text { Nomor Rak } \\
\text { Yang Diatur } \\
\text { Ke Set } \\
\text { Point }\end{array}$ & $\begin{array}{c}\text { Nomor Rak Yang } \\
\text { Seharusnya Diatur } \\
\text { Ke Set Point }\end{array}$ \\
\hline 1 & A & Titip & Titip & 0 & 0 \\
\hline 2 & B & Titip & Titip & 3 & 3 \\
\hline 3 & C & Titip & Titip & 4 & 4 \\
\hline 4 & B & Ambil & Ambil & 3 & 3 \\
\hline 5 & D & Titip & Titip & 3 & 3 \\
\hline 6 & A & Ambil & Ambil & 0 & 0 \\
\hline 7 & C & Ambil & Ambil & 4 & 4 \\
\hline 8 & D & Ambil & Ambil & 3 & 3 \\
\hline 9 & E & Titip & Titip & 0 & 3 \\
\hline 10 & A & Titip & Titip & 3 & 4 \\
\hline 11 & B & Titip & Titip & 4 & 1 \\
\hline 12 & D & Titip & Titip & 1 & 2 \\
\hline 13 & C & Titip & Titip & 2 & 5 \\
\hline 14 & F & Titip & Titip & 5 & 4 \\
\hline 15 & B & Ambil & Ambil & 4 & \\
\hline
\end{tabular}

Berdasarkan Tabel 9, dapat disimpulkan bahwa algoritma untuk menentukan nomor rak sudah benar. Adapun dari tabel tersebut dapat diketahui bahwa satu kartu RFID hanya dapat mengakses satu rak. Dari hal tersebut dapat disimpulkan bahwa prototipe tempat penitipan barang ini dapat meningkatkan keamanan karena satu rak hanya dapat diakses oleh satu RFID. Artinya barang dari setiap pengguna hanya dapat diakses oleh pengguna tersebut.

\section{KESIMPULAN}

Berdasarkan hasil pengujian dan analisis, troli rotari dengan metode FLC dapat mengontrol posisi rak dengan beban berbeda pada beberapa rak. Dengan pengujian yang dilakukan, hasil yang paling optimal diperoleh dari fungsi keanggotaan keluaran variasi 3 dengan settling time yang diperoleh antara 2,96 - 4,66 sekon dan error steady state antara -14 - 11 counter. FLC yang dirancang menggunakan dua masukan yaitu error (e) posisi dan delta error $(\Delta \mathrm{e})$ posisi. Masukan tersebut cukup untuk merepresentasikan posisi rak dan perpindahan rak terhadap satu loop program. Dengan kata lain, perpindahan rak terhadap satu loop program yaitu representasi dari resultan gaya berat total yang bekerja pada sistem. Adapun keluaran FLC 
berupa singleton karena perhitungan yang sederhana pada mikrokontroler. Pada pengujian FLC dengan beban berbeda pada beberapa rak, diperoleh settling time antara 2,76 - 4,66 sekon dan error steady state antara -14 - 11 counter. Settling time dan error steady state pada setiap pengujian dipengaruhi oleh beban yang berbeda pada beberapa rak. RFID pada troli rotari berfungsi sebagai sistem akses rak. Berdasarkan algoritma sistem ini, suatu rak dengan nomor tertentu hanya dapat diakses oleh kartu RFID yang telah ditandai pada nomor rak tersebut.

\section{DAFTAR RUJUKAN}

Al Masyhur, A. R. (2015). Rancang Bangun Loker Penitipan Barang Menggunakan Barcode KTM dan PIC Berbasis Arduino. Malang: Universitas Muhammadiyah Malang.

Almatheel, Y. A., \& Abdelrahman, A. (2017). Speed Control of DC Motor Using Fuzzy Logic Controller. International Conference on Communication, Control, Computing and Electronics Engineering, (pp. 1-8).

Ismail, N., Nursalim, I., Saputra, H. M., \& Gunawan, T. S. (2018). Implementation of Fuzzy Logic Control System on Rotary Car Parking System Prototype. Indonesian Journal of Electrical Engineering and Computer Science, 12(2), 706-715.

Kusumadewi, S., \& Hartati, S. (2010). Neuro-Fuzzy Integrasi Sistem Fuzzy \& Jaringan Syaraf. Yogyakarta: Graha Ilmu.

Malau, H. R., Sumaryo, S., \& Darlis, D. (2011). Perancangan Sistem Monitoring Dan Implementasi Miniatur Lift Cerdas. Bandung: Universitas Telkom.

Mohamed, A. B., Mahmoud, A. I., \& Eid, A. M. (2016). Rotary Smart Parking System Using PLC. Pyramids Higher Institute for Engineering and Technology.

Nugraha, M. B., Priramadhi, R. A., \& Darlis, D. (2015). Design and Implementation of RFID Line-Follower Robot System with Color Detection Capability using Fuzzy Logic. The 2015 International Conference on Control, Electronics, Renewable Energy, and Communication (ICCEREC 2015) (pp. 75 - 78). Bandung: IEEE.

Nurega, P., Subekti, R., \& Nugraha, N. W. (2016). Rancang Bangun Sistem Kendali Parkir Rotasi Vertikal Berbasis RFID Untuk Sistem Parkir Pintar. Seminar Nasional Teknik Kendali dan Manufaktur 2016, (pp. A42 - A47).

Open Library Universitas Telkom. (2017). Gallery Open Library Telkom. Dipetik Desember 6, 2019, dari HIS Travel: https://openlibrary.telkomuniversity.ac.id/

Pangaribuan, P., \& Darlis, D. P. (2018). Implementation of the Sun Tracker System with fuzzy logic on solar panels. VOLT : Jurnal IImiah Pendidikan Teknik Elektro, 3(2), 78-84.

Patel, C., Swami, M., Saxena, P., \& Shah, S. (2015). Rotary Automated Car Parking System. International Journal of Engineering Science and Innovative Technology, 4(2), 408415. 
Putra, A. I., Purwanto, \& Siswojo, B. (2013, Juli). Sistem Pengaturan Posisi Sudut Putar Motor DC Pada Model Rotary Parking Menggunakan Kontroler PID Berbasis Arduino Mega 2560. Jurnal Mahasiswa TEUB, 1(3), 1-7.

Rizki, A. S., Pangaribuan, P., \& Wibowo, A. S. (2018). Perancangan Sistem Kendali Untuk Kestabilan Pendulum Terbalik Menggunakan Metode Logika Fuzzy. eProceedings of Engineering. 5, (pp. 9-12).

Sodiq, M., \& Hasbullah, H. (2017). Prototype of Arduino Based Parking Rotation System. International Symposium on Materials and Electrical Engineering. 384, (pp. 1-9).

Wida, C. (2012). Implementasi Fuzzy Logic Controller Untuk Pengendalian Level Air. Jurnal ELEKTRAN, 2(1), 20-24. 